\title{
PENGARUH PENAMBAHAN TEMBAGA (Cu) TERHADAP SIFAT LISTRIK POLIANILIN (PANi)
}

\author{
Astuti, Henny Prastiwi \\ Laboratorium Fisika Material. Jurusanan Fisika. Universitas Andalas \\ Kampus Unand. Limau Manis. Padang \\ Email : tuty_phys@yahoo.com
}

\begin{abstract}
ABSTRAK
Penelitian ini bertujuan untuk menganalisis pengaruh penambahan serbuk tembaga $(\mathrm{Cu})$ terhadap nilai konduktivitas dan energi gap PANi-Cu. Pengukuran konduktivitas ini dilakukan dengan variasi suhu yaitu $298 \mathrm{~K}$ dan $373 \mathrm{~K}$. Kenaikan suhu pada saat pengukuran menyebabkan peningkatan konduktivitas bahan tersebut. Konduktivitas pada suhu tertinggi yaitu $373 \mathrm{~K}$ dengan konduktivitas antara 4,46 x 10-4 S/cm - 8,92 x 10-4 S/cm untuk semua variasi konsentrasi serbuk tembaga yaitu 0,$1 ; 0,3$, dan 0,5 gr. Berbanding terbalik dengan energi gap, yaitu semakin banyak komposisi serbuk tembaga yang ditambahkan mengakibatkan penurunan energi gap pada komposit PANi-Cu. Nilai energi gap yang dihasilkan adalah 0,32-0,8 eV untuk semua variasi doping tembaga terhadap PANi.
\end{abstract}

Kata Kunci : Polianilin (PANi), Tembaga, Konduktivitas, Energi Gap

\section{PENDAHULUAN}

Polimer konduktif adalah polimer yang dapat menghantarkan arus listrik. Hantaran listrik terjadi karena adanya elektron ikatan terdelokalisasi yang mempunyai struktur pita seperti silikon. Polimer konduktif kebanyakan bersifat semikonduktor dimana struktur pitanya mirip dengan struktur pita silikon (Sze, 1985). Keuntungan dari polimer konduktif antara lain: merupakan gabungan dari sifat logam dan polimer, mempunyai konduktivitas tinggi, transparan, harga terjangkau dan mudah disintesis. (Shirakawa, 2001).

Polianilin (PANi) merupakan salah satu polimer konduktif yang banyak dikembangkan saat ini. Pada tahun 1989 telah dilaporkan bahwa PANi dapat menunjukkan fenomena elektronik yang sangat fleksibel yaitu dapat bersifat sebagai isolator sampai konduktor. PANi memiliki keunggulan dari segi sifat kimia dan fisika, mekanisme sintesis, serta perkembangan aplikasinya seperti baterai sekunder, sensor, LED dan bidang optoelektronik. Polimer konduktif memiliki potensi yang cukup besar untuk berbagai macam aplikasi. Bahan polimer konduktif sangat unik yaitu dapat mengalami perubahan sifat listrik dan optik yang dapat kembali (reversible) melalui reaksi redoks dan dopingdedoping atau protonasi-deprotonasi sehingga sangat potensial dimanfaatkan pada berbagai aplikasi (Ansari, dkk, 2006; Bhullar, 2009).

Sejauh ini, bahan PANi telah digunakan pada berbagai aplikasi seperti sensor kimia khususnya sensor gas, piranti elektronik, sel fotovoltaik, LED polimer dan baterai sekunder (Tamburri, dkk, 2012; Xin, dkk, 2007). Proses pendopingan PANi tidak hanya terbatas pada jenis produk asam-asam protonik saja, melainkan dapat juga didoping dengan logam-logam yang memiliki nilai konduktivitas cukup tinggi (Ozkazanc, dkk, 2010; Jain, dkk, 2006). Selain itu, Valsangiacom dkk (2004) juga telah meneliti adanya peningkatan konduktivitas PANi dengan doping logam besi (Fe). Beberapa modifikasi sintesis PANi juga telah dilakukan oleh para peneliti, seperti dengan wet spinning technique (Mirmohseni, dkk, 2006), dengan menggunakan metode elektrokimia 
(Vivekanandan, dkk, 2011), maupun dengan metode polimerisasi (Chauhan, dkk, 2011; Tamburri, dkk, 2012).

Pada penelitian ini PANI disintesis dalam bentuk Emeraldine Base (EB) atau Emeraldine Salt (ES), karena EB merupakan bentuk yang paling stabil dan paling banyak diteliti karena konduktivitasnya dapat diatur (Chauhan, dkk, 2011). Sintesis ini akan dilakukan dalam 2 tahap dimana tahap pertama adalah sintesis pembuatan PANi murni (PANi-ES) kemudian mendopingnya dengan serbuk tembaga. Serbuk tembaga yang digunakan dalam penelitian ini adalah serbuk tembaga murni yang berasal dari pembubutan lempengan tembaga dan garam $\mathrm{CuSO}_{4}$ yang berbentuk butiran-butiran kristal. Penambahan tembaga kedalam PANi dapat mempengaruhi sifat listrik bahan secara keseluruhan. Konduktivitas adalah sifat listrik yang dianalisis dalam penelitian ini, dimana konduktivitas listrik dapat dihitung dengan menggunakan Persamaan 1.

$$
\sigma=\frac{L}{R A}
$$

dengan $\sigma$ adalah konduktivitas listrik suatu bahan $(\Omega m)^{-1}, \rho$ adalah resistivitas suatu bahan $(\Omega \mathrm{m}), R$ adalah resistansi suatu bahan $(\Omega), L$ adalah panjang cuplikan pengukuran sampel $(\mathrm{m})$ dan $A$ adalah luas penampang sampel $\left(\mathrm{m}^{2}\right)$. Selain penentuan konduktivitas, juga dilakukan penentuan energi gap dari sampel PANi murni maupun PANi yang didoping dengan serbuk $\mathrm{Cu}$ dan $\mathrm{CuSO}_{4}$ dengan menggunakan Persamaan 2.

$$
\ln \sigma=\ln \sigma_{0}-\left(\frac{E_{g}}{2 k_{b}}\right) \frac{1}{T}
$$

Dengan $\sigma$ adalah konduktivitas sampel pada variasi suhu, $\sigma_{0}$ adalah nilai konduktivitas sampel tanpa variasi suhu, $k_{b}$ adalah nilai Konstanta Boltzman $E_{g}$ adalah energi gap dan T adalah suhu dalam Kelvin. Berdasarkan persamaan tersebut pengukuran konduktivitas pada berbagai suhu akan menghasilkan grafik $\ln \sigma_{0}$ terhadap 1/T. Lebar celah energi $E_{g}$ dapat ditentukan dari kemiringan (slope) grafik tersebut.

\section{METODELOGI PENELITIAN}

PANi dapat disintesis melalui metode polimerisasi oksidasi secara kimia. Metode oksidasi kimia merupakan metode sintesis yang sederhana pada suhu ruang dan menghasilkan PANi dalam skala besar. Sintesis PANi dilakukan dengan cara mencampurkan $50 \mathrm{~mL} \mathrm{HCl}$ dengan $2 \mathrm{~mL}$ monomer anilin selama 1 jam. Sementara itu dalam waktu yang bersamaan 6 gr Ammonium Peroksidisulfat $(\mathrm{NH})_{4} \mathrm{~S}_{2} \mathrm{O}_{8}$ dimasukkan ke dalam $50 \mathrm{~mL}$ aquades selama 1 jam. Kedua larutan tersebut dicampurkan ke dalam satu wadah kimia, diaduk dan dibiarkan selama 2 jam sampai terjadi polimerisasi sempurna dengan terbentuk endapan berwarna hijau dan terlihat terpisah, larutan $\mathrm{HCl}$-Anilin berada di atas dan larutan $\mathrm{H}_{2} \mathrm{O}-(\mathrm{NH})_{4} \mathrm{~S}_{2} \mathrm{O}_{8}$. Produk yang berupa endapan kemudian dibilas dengan menggunakan $\mathrm{HCl}$ sebanyak 3 kali dan kemudian dibilas lagi menggunakan aseton sebanyak 3 kali sehingga terbentuk endapan PANi hidroklorid (Emeraldine Salt). Kemudian polianilin tersebut dikeringkan dengan pemanasan pada suhu $80{ }^{\circ} \mathrm{C}$ selama 2 jam.

Serbuk PANi hasil sintesis didoping dengan serbuk tembaga dengan komposisi $0,1 \mathrm{gr}$, 0,3 gr dan 0,5 gr. Setelah proses pendopingan dilakukan, serbuk PANi-Cu tersebut dikompaksi dengan dengan ketebalan tablet $1 \mathrm{~mm}$, sehingga hasil akhir yang diperoleh berupa tablet PANi-Cu yang selanjutnya dilakukan karakterisasi sifat listriknya. Proses pengukuran tersebut menggunakan tegangan masukan $\mathrm{V}_{\text {in }}$ dipasang sebesar 12 volt, 
panjang cuplikan pengukuran $0,7 \mathrm{~cm}$ dengan luas penampang sampel adalah sebesar $0,785 \mathrm{~cm}^{2}$. Diagram alir penelitian ini dapat dilihat pada Gambar 1 .

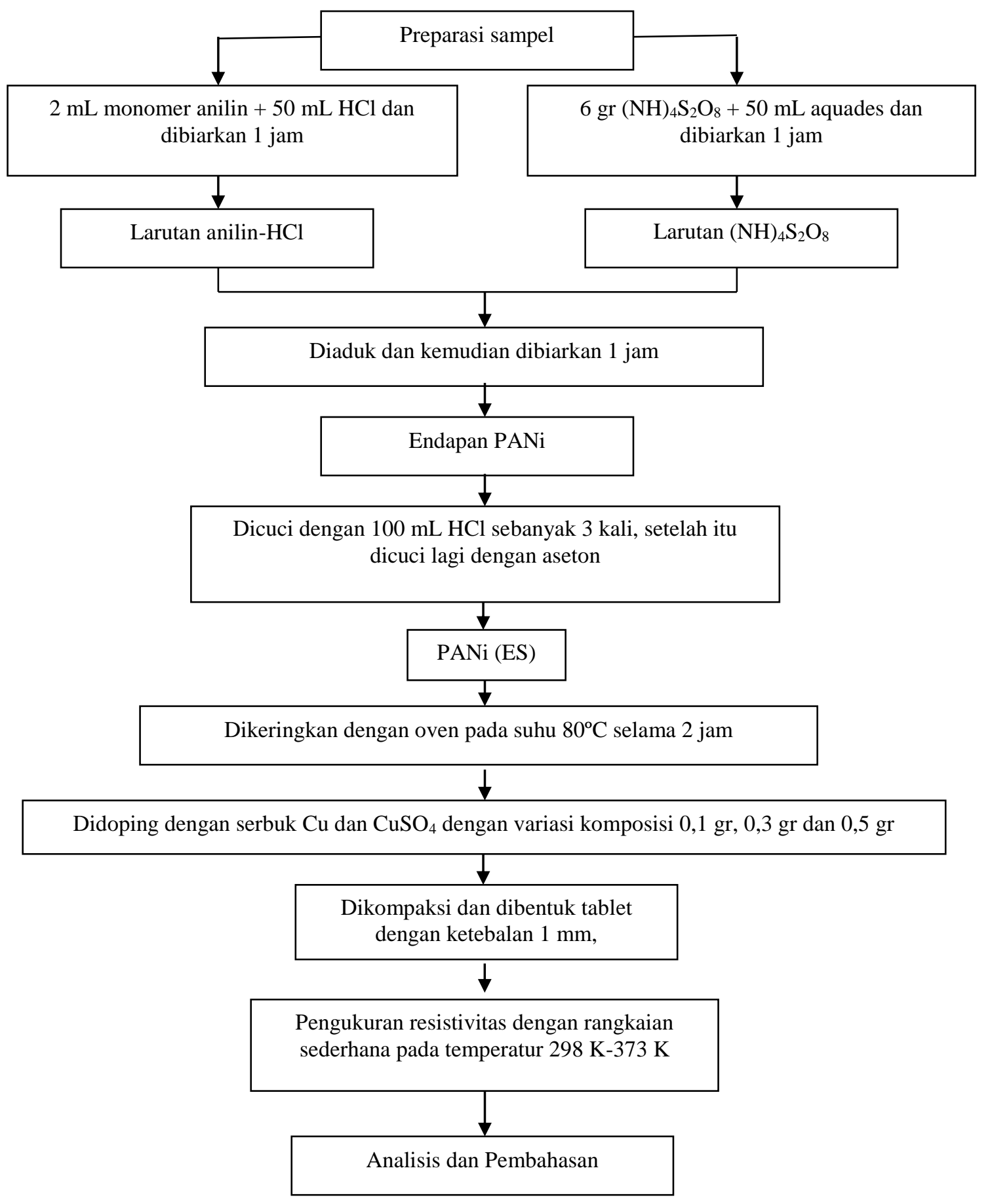

Gambar 1. Diagram alir penelitian

\section{HASIL DAN PEMBAHASAN Penentuan konduktivitas}

Perbandingan nilai konduktivitas sampel PANi murni dan PANi yang didoping dengan serbuk tembaga (PANi-Cu) dengan variasi suhu dapat dilihat pada Tabel 1. 
Tabel 1. Nilai konduktivitas PANi dan PANi-Cu

\begin{tabular}{ccccc}
\hline \multirow{2}{*}{$\begin{array}{c}\text { Suhu } \\
(\mathrm{K})\end{array}$} & \multicolumn{4}{c}{ Konduktivitas $\times 10^{-4} \mathrm{~S} / \mathrm{cm}$} \\
\cline { 2 - 5 } & $\begin{array}{c}\text { PANi } \\
\text { murni }\end{array}$ & $\begin{array}{c}\text { PANi }+ \\
0,1 \mathrm{gr} \mathrm{Cu}\end{array}$ & $\begin{array}{c}\text { PANi }+ \\
0,3 \mathrm{gr} \mathrm{Cu}\end{array}$ & $\begin{array}{c}\text { PANi }+ \\
0,5 \mathrm{gr} \mathrm{Cu}\end{array}$ \\
\hline 298 & 0.61 & 0.69 & 0.87 & 1.05 \\
\hline 303 & 0.74 & 0.70 & 1.10 & 1.14 \\
\hline 308 & 0.87 & 0.74 & 1.19 & 1.24 \\
\hline 313 & 0.94 & 0.76 & 1.26 & 1.27 \\
\hline 318 & 1.24 & 0.78 & 1.46 & 1.49 \\
\hline 323 & 1.44 & 0.80 & 1.56 & 1.59 \\
\hline 328 & 1.54 & 0.83 & 1.62 & 1.65 \\
\hline 333 & 1.65 & 0.87 & 1.82 & 1.86 \\
\hline 338 & 2.18 & 0.94 & 2.23 & 2.23 \\
\hline 343 & 2.79 & 0.99 & 2.29 & 2.41 \\
\hline 348 & 2.97 & 1.03 & 2.41 & 2.62 \\
\hline 353 & 3.19 & 1.09 & 2.88 & 2.88 \\
\hline 358 & 3.57 & 1.13 & 3.30 & 3.43 \\
\hline 363 & 4.95 & 1.19 & 5.25 & 5.57 \\
\hline 368 & 5.95 & 1.29 & 5.57 & 6.37 \\
\hline 373 & 7.43 & 1.56 & 7.43 & 7.43 \\
\hline
\end{tabular}

Berdasarkan nilai konduktivitas yang ada pada Tabel 1, maka dapat dibuat perbandingan hubungan suhu terhadap konduktivitas antara sampel PANi murni dengan PANi-Cu seperti Gambar 2.

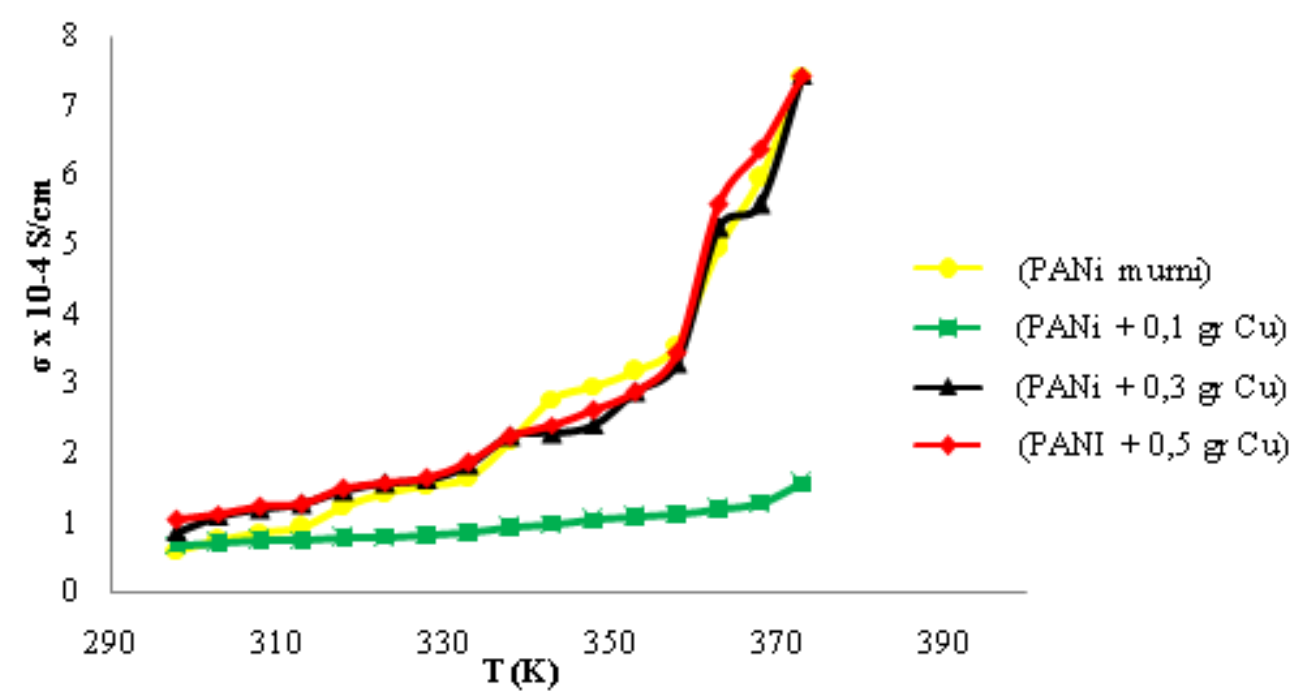

Gambar 2. Grafik hubungan suhu terhadap konduktivitas pada PANi-Cu

Pada Tabel 1 dan Gambar 2, terlihat bahwa konduktivitas sebanding dengan suhu yang diberikan, dimana semakin tinggi suhu maka nilai konduktivitas dari masing-masing sampel juga mengalami kenaikan, baik sampel yang tidak didoping maupun yang didoping dengan $\mathrm{Cu}$. Berdasarkan hasil penelitian yang diperoleh, terlihat bahwa nilai konduktivitas sampel PANi murni mengacu kepada nilai konduktivitas PANi murni tanpa perlakuan doping yang ada pada penelitian-penelitian sebelumnya yaitu berkisar antara $10^{-10} \mathrm{~S} / \mathrm{cm}$ sampai $100 \mathrm{~S} / \mathrm{cm}$ (Indah dkk, 2010). Sementara hasil penelitian ini diperoleh dengan variasi suhu berkisar antara $0,61 \times 10^{-4} \mathrm{~S} / \mathrm{cm}$ sampai dengan $7,4 \times 10^{-4} \mathrm{~S} / \mathrm{cm}$. 
Kenaikan konduktivitas juga disebabkan oleh kenaikan suhu, dimana atom-atom yang menyusun sampel tersebut bervibrasi. Getaran yang terjadi pada atom-atom tersebut menimbulkan jarak antar atom yang semakin besar, sehingga atom tidak mudah mengikat elektron dan mengakibatkan elektron mudah bergerak bebas. Gerakan elektron bebas ini akan meningkatkan konduktivitas listrik dari sampel tersebut (Parno, 2006).

Selain pengaruh suhu, kenaikan konduktivitas juga disebabkan oleh doping atau penyisipan serbuk $\mathrm{Cu}$ pada PANi. Hal ini disebabkan oleh konduktivitas $\mathrm{Cu}$ jauh lebih besar dibanding PANi murni. Semakin besar konsentrasi doping yang diberikan nilai konduktivitas semakin meningkat. Lain halnya dengan sampel PANi yang didoping dengan serbuk 0,1 gr serbuk $\mathrm{Cu}$, dimana terjadi penurunan konduktivitas jika dibandingkan dengan PANi murni. Hal ini berkemungkinan disebabkan oleh sebaran partikel dari serbuk $\mathrm{Cu}$ ke dalam serbuk PANi tidak merata. Pada penelitian sebelumnya juga dijelaskan bahwa penambahan dopan berupa logam juga dapat meningkatkan konduktivitas PANi seperti yang dilakukan oleh Valsangiacom dkk (2004), dimana nilai konduktivitas yang diperoleh dari proses pendopingan PANi dengan serbuk besi (Fe) adalah sebesar $10 \mathrm{~mW} / \mathrm{cm}^{2}$. Berdasarkan penelitian yang lain, secara keseluruhan konduktivitas polimer (PANi) yang mengalami proses pendopingan ini dipengaruhi oleh beberapa faktor, yaitu konsentrasi dopan yang ditambahkan, homogenitas dopan dalam $\mathrm{PANi}$, derajat kristalinitas, dan morfologi polimer serta reaksi kimia yang terjadi antara dopan dengan polimer itu sendiri (Bhullar, 2009).

\section{Penentuan Energi Gap}

Tabel 2. Nilai hubungan $\ln \sigma$ terhadap $1 / \mathrm{T}$ antara PANi dengan PANi-Cu

\begin{tabular}{ccccc}
\hline \multirow{2}{*}{$1 / \mathrm{T}$} & \multicolumn{4}{c}{$\ln \sigma$} \\
\cline { 2 - 5 }$\left(\mathrm{K}^{-1}\right)$ & \multirow{2}{*}{ PANi murni } & $\begin{array}{c}\text { PANi }+ \\
0,1 \mathrm{gr} \mathrm{Cu}\end{array}$ & $\begin{array}{c}\text { PANi }+ \\
0,3 \mathrm{gr} \mathrm{Cu}\end{array}$ & $\begin{array}{c}\text { PANi }+ \\
\text { gr Cu }\end{array}$ \\
\hline 0.00336 & -5.02068563 & -4.9747856 & -4.7490406 & -4.6470344 \\
\hline 0.0033 & -4.90627528 & -4.9504814 & -4.5089513 & -4.391673 \\
\hline 0.00325 & -4.74443225 & -4.8245708 & -4.4320576 & -4.391673 \\
\hline 0.00319 & -4.66704559 & -4.5337802 & -4.3772381 & -4.3630086 \\
\hline 0.00314 & -4.42284863 & -4.2580407 & -4.3192396 & -4.3489788 \\
\hline 0.0031 & -4.26869795 & -4.1753377 & -4.2889007 & -4.2889007 \\
\hline 0.00305 & -4.19970508 & -4.1401791 & -4.2587476 & -4.2419169 \\
\hline 0.003 & -4.13516656 & -4.0524352 & -4.2090822 & -4.2253648 \\
\hline 0.00296 & -3.81671283 & -3.8281415 & -4.1579235 & -4.1753377 \\
\hline 0.00292 & -3.57555077 & -3.7255434 & -4.0466979 & -4.1221269 \\
\hline 0.00287 & -3.54045945 & -3.6408515 & -4.0064436 & -4.0851866 \\
\hline 0.00283 & -3.44201938 & -3.3729015 & -3.5487697 & -3.8281415 \\
\hline 0.00279 & -3.32423634 & -3.2501085 & -3.410339 & -3.7783666 \\
\hline 0.00275 & -3.01593498 & -2.9478949 & -3.3334453 & -3.410339 \\
\hline 0.00272 & -2.83021784 & -1.9063626 & -3.0590981 & -3.3334453 \\
\hline 0.00268 & -2.60369019 & -0.8077503 & -2.5995097 & -3.0590981 \\
\hline
\end{tabular}

Berdasarkan data yang diperoleh pada Tabel 2 dapat dibuat grafik hubungan $\ln \sigma$ terhadap 1/T antara PANi dengan PANi-Cu seperti pada Gambar 3. 


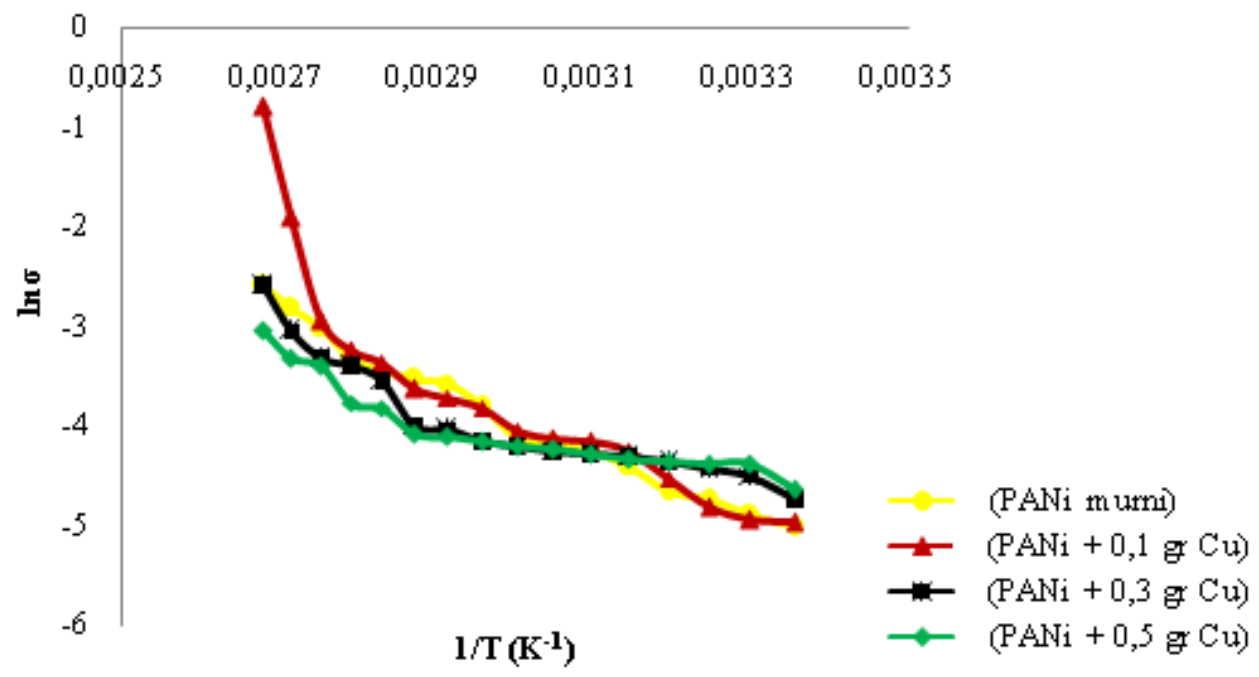

Gambar 3 Grafik hubungan $\ln \sigma$ terhadap 1/T antara PANi dengan PANi-Cu

Energi gap dari setiap sampel PANi-Cu tersebut dapat dihitung dengan menggunakan Persamaan 2. Energi gap yang diperoleh sampel PANi murni dengan PANi-Cu yang dapat dilihat pada Tabel 3 .

Tabel 3. Nilai energi gap antara PANi dengan PANi-Cu

\begin{tabular}{cc}
\hline Sampel & Eg $(\mathbf{e V})$ \\
\hline $\mathrm{B}(\mathrm{PANi}+0,1$ gr Cu$)$ & 0,8 \\
\hline $\mathrm{C}(\mathrm{PANi}+0,3$ gr $\mathrm{Cu})$ & 0,44 \\
\hline $\mathrm{D}(\mathrm{PANi}+0,5$ gr $\mathrm{Cu})$ & 0,32 \\
\hline
\end{tabular}

Penambahan konsentrasi $\mathrm{Cu}$ terhadap PANi dapat meningkatkan konduktivitas komposit PANi-Cu. Hal ini disebabkan oleh sifat logam dari $\mathrm{Cu}$ itu sendiri yang mempunyai mobilitas elektron yang tinggi sehingga mudah menghantarkan arus. Berbanding terbalik dengan konduktivitasnya, dimana peningkatan konsentrasi $\mathrm{Cu}$ menurunkan energi gap. Hubungan antara energi gap dengan konduktivitas adalah, semakin sempit energi gap maka, elektron akan lebih mudah untuk tereksitasi sehingga meningkatkan mobilitas elektron tersebut, artinya konduktivitas juga meningkat.

\section{KESIMPULAN}

Berdasarkan hasil penelitian yang telah dilakukan, yaitu melihat pengaruh penambahan serbuk tembaga terhadap sifat listrik polianilin (PANi) diperoleh kesimpulan bahwa, penambahan komposisi serbuk $\mathrm{Cu}$ PANi mempengaruhi sifat listrik dari PANi. Pengukuran konduktivitas dengan variasi suhu, menunjukkan peningkatan konduktivitas terhadap kenaikan suhu. Semakin banyak komposisi serbuk $\mathrm{Cu}$ yang ditambahkan nilai energi gapnya semakin menurun. Nilai energi gap PANi yang dihasilkan melalui doping dengan $\mathrm{Cu}$ berkisar antara $0,32-0,8 \mathrm{eV}$.

\section{REFERENSI}

1. Ansari, R.\& Keivani, MB. 2006. Polyaniline conducting electroactive polymers: thermal and Environmental Stability Studies. E-Journal of Chemistry. Vol. 3. No. 4. Pages 202-217.

2. Bhullar, G.K. 2009. Synthesis and Characterization of Conducting Polymer Polyaniline. Thesis. Thapar University. India. 
3. Chauhan, NPS. Ameta, R. Ameta, R. Ameta, S. 2011. Thermal and Conducting Behavior of Emeraldine Base (EB) Form of Polyaniline (PANI). Indian Journal of Chemistry, Vol. 18.

4. Indah. P.D, Salindia. P.E, Utami. N, 2010, Upaya Pembuatan Bahan Elastis Transparan Konduktif Berbasis Bahan Polianilin (PANi/Fe). Universitas Negeri Malang.

5. Jain, N. Patidar, D. Saxena, N.S \& Sharma, K. 2006. Temperature dependence of dc conductivity in polyaniline-metal halide composites. Indian Journal of Pure \& Applied Physics, Vol. 44. pages. 767-770.

6. Mirmohseni. A, Salari. D, Nabaul. R. 2006. Preparation of Conducting Polyaniline/Nylon 6 Blend Fibre By Wet Spinning Technique. J. Iranian polymer, 15(3), pages 259-264.

7. Ozkazanc, E. Zor, S. and Ozkazanc, H. 2010. Effect of metal cations on the dielectric properties of polyaniline, 10.1002/spepro.002879,. Plastics Research Online, 10.1002/spepro.002879

8. Parno, 2006, Fisika Zat Padat: Struktur Kristal, Universitas Negeri Malang.

9. Shirakawa, H. 2001. Nobel Lecture: The discovery of Polyacetilene film-the dawning of an era of conducting polymer. University of Tsukuba. Japan.

10. Sze, S.M. 1985. Physics of Semiconductor Devices. Second Edition. John Wiley and Sons.

11. Tamburri, E. Guglielmotti, V Orlanducci, S. Terranova, M. L. Sordi, D. Passeri, D. Matassa, R. Rossi, M. 2012. Nanodiamond-mediated crystallization in fibers of PANI nanocomposites produced by template-free polymerization: Conductive and thermal properties of the fibrillar networks. Polymer. Volume 53. Pages 4045-4053.

12. Vasangiacom, C. Sima, M. Plapcianu, D.P.C. Kuncser, C. Schinteie, G. Bulinski, M. 2004. A Microscopic Analyze Of The Conduction Mechanism Of Iron Doped Polyaniline Under The UV Exposure. Romanian Report in Physics. Vol. 56. No. 4. Pages 654-650.

13. Vivekanandan, J. Ponnusamy, V. Mahudeswaran, A. and Vijayanand, P.S. 2011. Synthesis, characterization and conductivity study of polyaniline prepared by chemical oxidative and electrochemical methods. Archives of Applied Science Research. Vol. 3. pages 147-153. Scholars research library.

14. Xin, L. Jiaoyan, S. Meixiang, W. Zhaojia, C. Yen, W. 2007. Core-shell structure And Electromagnetic Functionalized Polyaniline Composites. Sciendirect. 